\title{
Editorial
}

\section{Malaria research in Brazil: we are doing well}

In this special issue fully dedicated to malaria research, we present a timely series of 21 manuscripts comprising reviews, original articles and opinions on an issue that still deserves much public health attention in most tropical and subtropical areas of the World, including Latin America. This sub-continent has been facing over the past decades a substantial epidemiological transition (Oliveira-Ferreira et al. 2010), which poses new challenges, such as the understanding of the biology and the more appropriate tools to control Plasmodium vivax, the less lethal parasite with clear evolutionary advantages such as generation of early gametocytes and long-living hypnozoites. In order to understand malaria dynamics in Latin America, a lot of innovation has been achieved due to scientific collaboration.

Malaria control seems to be a reality in Latin America. Nonetheless, it is now essential to step up the pace and take decisions towards the ambitious goal of eliminating malaria from this continent. Malaria eradication has gained renewed interest since 2007, and for those who are skeptical, the debate is not new. Most of the Brazilian leaderships in the fight against this disease, such as Prof. Leônidas Deane and Prof. Heitor Dourado, were actually skilled during malaria eradication campaigns (Deane 1988, Najera et al. 2011). In 1960, the editorial of the British Medical Journal pointed out to efficient vector control as a powerful tool for malaria eradication, but also called the attention for the threat posed by introduction of competent exotic vectors, such it was the case of Anopheles gambiae in northeastern Brazil (Editorial 1960). In that same year, a very aggressive letter to the editor stated the need for new strategies on antimalarials use to tackle malaria, giving as an example the pioneer idea of the Brazilian physician Mário Pinotti of adding chloroquine to the cooking salt (Heisch 1960). Actually they were both right, and the efforts needed to be synergistic and sustainable, what did not happen. However, new drugs will be available in the near future such as tafenoquine, a new 8-aminoquinoline with activity against blood and tissue stages of both Plasmodium falciparum and $P$. vivax malaria, achievable with single doses which can make the goal of eradication even more real (Llanos-Cuentas et al. 2014).

In the fight against malaria, innovation is urgently needed. The use of new tools such as metabolomics analysis, specially validating experimental animal models, is already an ongoing approach. The challenging $P$. vivax poses difficulties such as clinical management of vulnerable populations (e.g., infants and pregnant women), as well as the emerging chloroquine resistance. Glucose-6-phosphate dehydrogenase deficiency is still a major limitation for massive use of drugs such as primaquine and tafenoquine, but the lack of this deficiency in Latin American indigenous populations is an advantage. The epidemiological features of the malaria in the Atlantic Forest area (Brazil extra-Amazon region) with the possibility of plasmodia of non-human primates to be naturally transmitted to humans (Deane 1988) and the lack of effective anopheline control measures (Maciel-de-Freitas et al. 2012) definitely compromises eradication goals and needs further clarification. Should Prof. Philip Marsden were alive in the present days, he would probably not be bothered at 02:30 am because of a severe falciparum malaria patient diagnosed outside the Amazon Region (Marsden 1989). However, it is highly important to still keep an eye on P. falciparum in these days, as it was a concern back there in 1910 (Neiva 1910), due to the real perspective of artemisinin resistance spread, considered by some the worst case scenario.

This is the fourth time that Memórias do Instituto Oswaldo Cruz launches a special issue entirely dedicated to malaria research. In 2013, during the 13th Brazilian Malaria Research Meeting held in Manaus, western Brazilian Amazon, many of the topics covered in the present malaria-specific issue were fully debated by students, junior and senior scientists from all over the world, as well as Latin American policy makers, in a desirable interdisciplinary approach. The Brazilian and other South American scientific communities devoted to malaria research have considerably been improving over the years. For instance, malaria research constitutes nowadays one of the most fruitful scientific investigation lines in Brazil, relying on qualified personnel and infrastructure both in and outside the endemic Amazon Region (Costa et al. 2012). With significant investments made in graduate and post-graduation programs, and in the international exchange of scientists responsible for technology transfer (Science without Borders Program), Brazil is proud to be part of Latin American countries, together with Peru, Colombia and French Guiana, amongst others, that substantially has contributed to improve the knowledge on several malaria-related topics in a competitive way. Brazilian scientific research in general is doing well and can be significantly improved in the next years. No doubt, the national expertise in malaria research and control over time seems to be part of this success. 


\section{REFERENCES}

Costa FT, Lopes SC, Albrecht L, Ataide R, Siqueira AM, Souza RM, Russell B, Renia L, Marinho CR, Lacerda MV 2012. On the pathogenesis of Plasmodium vivax malaria: perspectives from the Brazilian field. Int J Parasitol 42: 1099-1105.

Deane LM 1988. Malaria studies and control in Brazil. Am J Trop Med Hyg 38: 223-230.

Editorial 1960. Eradication of malaria. Br Med J 1: 1033-1034.

Heisch RB 1960. Eradication of malaria. Br Med J 1: 1736.

Llanos-Cuentas A, Lacerda MV, Rueangweerayut R, Krudsood S, Gupta SK, Kochar SK, Arthur P, Chuenchom N, Mohrle JJ, Duparc S, Ugwuegbulam C, Kleim JP, Carter N, Green JA, Kellam L 2014. Tafenoquine plus chloroquine for the treatment and relapse prevention of Plasmodium vivax malaria (DETECTIVE): a multi- centre, double-blind, randomised, phase $2 \mathrm{~b}$ dose-selection study. Lancet 383: 1049-1058.

Maciel-de-Freitas R, Aguiar R, Bruno RV, Guimarães MC, Lourençode-Oliveira R, Sorgine MHF, Struchiner CJ, Valle D, O'Neill SL, Moreira LA 2012. Why do we need alternative tools to control mosquito-borne diseases in Latin America? Mem Inst Oswaldo Cruz 107: 828-829.

Marsden PD 1989. Growing problem of malaria. Br Med J 299: 1328-1329.

Najera JA, Gonzalez-Silva M, Alonso PL 2011. Some lessons for the future from the Global Malaria Eradication Programme (19551969). PLoS Med 8: e1000412.

Neiva A 1910. Formacäo de raca do hematozoario do impaludismo rezistente a quinina. Mem Inst Oswaldo Cruz 2: 131-140.

Oliveira-Ferreira J, Lacerda MV, Brasil P, Ladislau JL, Tauil PL, DanielRibeiro CT 2010. Malaria in Brazil: an overview. Malar J 9: 115.

Marcus VG Lacerda

Fabio TM Costa

Invited Editors for this issue

Ricardo Lourenço-de-Oliveira

Editor 